\section{Commentary: The cervical esophagogastric anastomosis: Augmenting training through simulation}

Ernest G. Chan, MD, MPH, James D. Luketich, MD, and Inderpal S. Sarkaria, MD, MBA

The cervical anastomosis is undoubtedly one of the most pivotal and technically important steps of the transhiatal esophagectomy (THE) and other approaches to esophagectomy. The success or failure of the anastomosis often directly parallels both short- and long-term outcomes following this procedure. The Michigan group has championed the THE for the past several decades, publishing excellent results in their series of 2000 THE. $^{1}$ They have continued to demonstrate improvement in their outcomes through evolving surgical techniques, as shown by an impressive $43 \%$ decrease in their anastomotic leak rate from $14 \%$ to $9 \%$ over time in their 2000 THE report, and even lower leak rates reported more recently. ${ }^{1,2}$

In an age in which surgical results are measured by a more detailed analysis of quality outcomes, surgical simulation promises to facilitate the training of cardiothoracic trainees to improve clinical and technical results. Many of these simulation-based curriculums have been reported to not only have a high fidelity to live surgery but also to impart skill sets to produce safer surgeons. ${ }^{3-6}$ In addition, in the current environment, residents have limitations imposed by duty hours, and attendings must be present for key portions of the procedures. Thus, true independence in the operating room has seen an overall decline from previous generations of trainees.

From the Department of Cardiothoracic Surgery, University of Pittsburgh School of Medicine and the University of Pittsburgh Medical Center, Pittsburgh, Pa.

Disclosures: Dr Luketich owns stock in Intuitive Surgical and Express Scripts. Dr Sarkaria is a speaker/educator for Intuitive Surgical. Dr Chan reported no conflicts of interest.

The Journal policy requires editors and reviewers to disclose conflicts of interest and to decline handling or reviewing manuscripts for which they may have a conflict of interest. The editors and reviewers of this article have no conflicts of interest.

Received for publication March 30, 2020; revisions received March 30, 2020; accepted for publication March 31, 2020; available ahead of print April 9, 2020.

Address for reprints: James D. Luketich, MD, Department of Cardiothoracic Surgery, Division of Thoracic and Foregut Surgery, University of Pittsburgh Medical Center, Pittsburgh, PA 15232 (E-mail: luketichjd@upmc.edu).

J Thorac Cardiovasc Surg 2020;160:1610-1

$0022-5223 / \$ 36.00$

Copyright (c) 2020 by The American Association for Thoracic Surgery

http://dx.doi.org/10.1016/j.jtcvs.2020.03.119

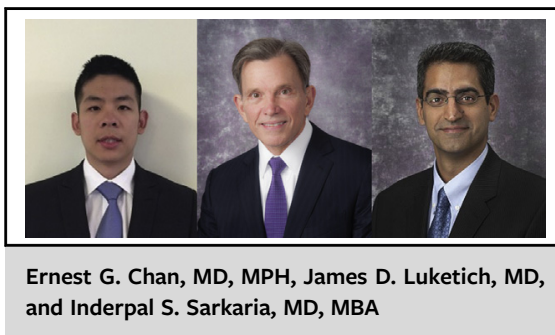

CENTRAL MESSAGE

In an age when quality is driven

by outcomes, surgical simulation

has helped facilitate the training

of cardiothoracic residents and

fellows to reproduce excellent

clinical and technical results.

In the current issue of the Journal, Orringer and colleagues ${ }^{7}$ introduce a novel simulator that facilitates the learning of the surgical skills necessary to perform a cervical esophagogastric anastomosis (CEGA) with high fidelity to live conditions. The authors describe the process of creating their cost-effective, high-fidelity simulator. Equally important with the actual physical simulator was the included curriculum created by a master surgeon to teach the stapled CEGA and ensure excellent and reproducible results. The authors further tested their simulator with both surgical staff as well as trainees, both of whom positively described the "lifelike feel of the esophagus" as well as the "realism of the experience." Both the authors' clinical experience and use of thorough trainee benchmarking provides a high level of confidence in translating the experience with the simulator to live surgery.

A recent study using the Society of Thoracic Surgeons' General Thoracic Surgery Database reported that nearly $46 \%$ of all 4321 esophagectomies performed at participating centers between 2012 and 2014 used an approach that required a CEGA. Therefore, we believe the CEGA simulator presented by Orringer and colleagues is a relevant and timely innovation. At our training program, we have adopted technology-enhanced approaches to surgical teaching that include real-time operative teaching, didactics, hands-on simulation, and use of biosynthetic as well as virtual models, all of which have helped prepare cardiothoracic trainees to perform complex operations. ${ }^{8}$ Likewise, the adoption of this novel CEGA simulator to the current training paradigm promises to augment the training of future cardiothoracic surgeons within today's guidelines. We applaud Orringer and colleagues at the University of 
Michigan, as they remain on the forefront in terms of teaching the art and science of esophageal surgery.

\section{References}

1. Orringer MB, Marshall B, Chang AC, Lee J, Pickens A, Lau CL. Two thousand transhiatal esophagectomies: changing trends, lessons learned. Ann Surg. 2007; 246:363-72; discussion 372-4.

2. Orringer MB, Marshall B, Iannettoni MD. Eliminating the cervical esophagogastric anastomotic leak with a side-to-side stapled anastomosis. J Thorac Cardiovasc Surg. 2000;119:277-88.

3. Fabian T, Glotzer OS, Bakhos CT. Construct validation: simulation of thoracoscopic intrathoracic anastomosis. JSLS. 2015;19.
4. Feins RH, Burkhart HM, Conte JV, Coore DN, Fann JI, Hicks GK, et al Simulation-based training in cardiac surgery. Ann Thorac Surg. 2017;103: 312-21.

5. Trehan K, Kemp CD, Yang SC. Simulation in cardiothoracic surgical training: where do we stand? J Thorac Cardiovasc Surg. 2014;147:18-24.e12.

6. Trehan K, Zhou X, Tang Y, Petrisor D, Kemp CD, Yang SC. THE GooseMan: a simulator for transhiatal esophagectomy. J Thorac Cardiovasc Surg. 2013;145: 1450-2.

7. Orringer MB, Hennigar D, Lin J, Rooney DM. A novel cervical esophagogastric anastomosis simulator. J Thorac Cardiovasc Surg. 2020;160:1598-607.

8. Chan PG, Schaheen LW, Chan EG, Cook CC, Luketich JD, D'Cunha J. Technology-enhanced simulation improves trainee readiness transitioning to cardiothoracic training. J Surg Educ. 2018;75:1395-402.
See Article page 1598.

\section{Commentary: Practice makes perfect in cervical esophagogastric anastomosis}

\author{
Nikhil Panda, MD, and Christopher R. Morse, MD
}

Cervical esophagogastric anastomotic leakage remains a serious complication after esophagectomy, with substantial impact on patient functional outcomes and quality of life. ${ }^{1,2}$ Although certain contributors to anastomotic breakdown, such as previously irradiated tissue and pre-existing patient comorbidities, are rarely modifiable at the time of an operation, surgical technique may be optimized before entering the operating theater through high-fidelity simulation training. ${ }^{3}$ Contemporary simulation training in cardiothoracic surgery ranges from simple bench prototypes to mixed-reality programs and cadaveric models. ${ }^{4}$ The majority focus on microvascular anastomosis, as well as bronchoscopic and endoscopic techniques. Few existing high-fidelity simulation tools are dedicated to open components of esophageal

From the Division of Thoracic Surgery, Department of Surgery, Massachusetts General Hospital, Boston, Mass.

Disclosures: Dr Panda reported a contract agreement with Aptima, a human-centered engineering and performance assessment contractor of the Defense Advanced Research Projects Agency, unrelated to the submitted work. Dr Morse reported a consulting agreement with Olympus, unrelated to the submitted work.

The Journal policy requires editors and reviewers to disclose conflicts of interest and to decline handling or reviewing manuscripts for which they may have a conflict of interest. The editors and reviewers of this article have no conflicts of interest.

Received for publication April 11, 2020; revisions received April 11, 2020; accepted for publication April 11, 2020; available ahead of print April 18, 2020.

Address for reprints: Christopher R. Morse, MD, Massachusetts General Hospital, 55

Fruit St, Founders 7, Boston, MA 02114 (E-mail: crmorse@partners.org).

J Thorac Cardiovasc Surg 2020;160:1611-2

$0022-5223 / \$ 36.00$

Copyright (c) 2020 by The American Association for Thoracic Surgery

http://dx.doi.org/10.1016/j.jtcvs.2020.04.018

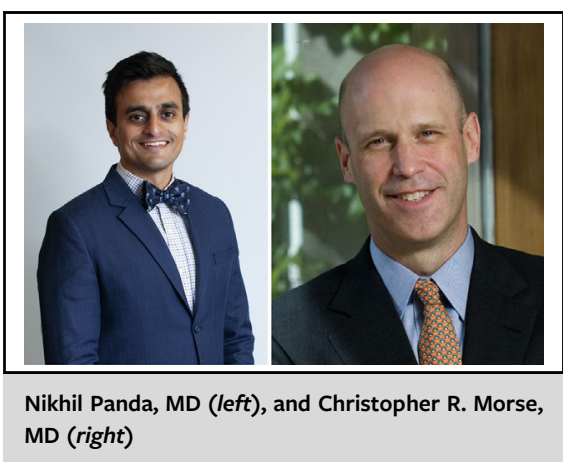

CENTRAL MESSAGE

A novel, purpose-built cervical esophagogastric simulation model designed for surgical education demonstrated fidelity among experienced thoracic surgeons and trainees.

operations, including the cervical esophagogastric reconstruction in the transhiatal or McKeown esophagectomy.

In this issue of the Journal, Orringer and colleagues ${ }^{5}$ introduce a novel, purpose-built cervical esophagogastric simulation model for use in thoracic surgical education. The simulation curriculum and bench model, both informed by the authors' extensive previous clinical experience and biomedical human-centered design principles, were then pilot tested for fidelity and feasibility first among 7 faculty and subsequently 8 thoracic surgery trainees. There was no difference in overall perceived value between experienced faculty and trainees. Combined observed averages among the 15 surgeon participants underscored the perceived value 